\title{
Blending Makes the Difference: Comparison of Blended and Traditional Instruction on Students' Performance and Attitudes in Computer Literacy
}

\author{
Adem Uzun \\ Aysan Senturk \\ Uludag University, Turkey
}

\begin{abstract}
Purpose of this study is to compare students' course achievement and attitudes towards computers in computer literacy course between two course delivery methods: Blended and face-to-face (FTF). Using a pretest-posttest control group experimental design model, participants were assigned to experimental and control groups purposefully in order to achieve group equivalency. The study was conducted during the fall of the 2006-2007 academic year. Participants were 179 students from the Faculty of Education at Uludag University in Turkey. 86 students were taught with the blended mode of delivery, which involved using both FTF and online modes of instruction; 93 students were taught with FTF mode alone. At the beginning of the study, prior knowledge about computer literacy and attitudes towards computers were measured in both groups. At the end of the study, students' final course scores and attitude scores towards computers were evaluated. Data were analyzed using independent samples t-tests. A statistically significant difference was found between the FTF and blended group $(p<0.05)$. The analysis showed that the blended group was more successful than the traditional group in terms of both course achievement and attitudes towards computers.
\end{abstract}

Keywords: Blended learning; Face-to-face instruction; Computer literacy; Attitudes toward computers

\section{Introduction}

\section{Background}

As the most popular form of distance education today, online learning is a rapidly growing trend in instructional technology. According to the United States Distance Learning Association and the Hale Group's report on distance learning, more than $96 \%$ of US colleges and universities now offer some form of online learning (US Report on Distance Learning, 2009). Online learning has become popular because of its strategic advantages, such as cost effectiveness and flexible learning environments.

Different forms of online education have been examined in the literature. Therefore, it is possible to identify numerous varieties of online education, such as online, web-based, webenhanced, blended, hybrid and mixed mode online learning. Since the concept of online learning is relatively new and there is no consortium that decides and defines all of these 
terms, different researchers have different points of view. Smith and Kurthen (2007) described today's distance learning concepts under four categories: web-enhanced, blended, hybrid learning and fully online. They stated that web-enhanced courses includes a minimal number of web-based elements, blended courses incorporate some online learning activities (less than $\% 45$ ). If online activities are between $45 \%$ and $80 \%$ then the course can be called hybrid. Classes with $80 \%$ or more e-learning are thought fully online. Allen and Seaman (2004) defined web-facilitated courses as those in which the proportion of content delivered online is less than $30 \%$. If the proportion is between $30 \%$ and $80 \%$, the course is defined as blended or hybrid. Finally, if the proportion is greater than $80 \%$, then the course is defined as fully online. Bourne, Harris, and Mayadas (2005) and Marsh, McFadden and Price (2003) defined blended learning as an optimal combination of face-to-face (FTF) and online education that improves learning and satisfaction of instructors and students at a reasonable cost. The concept of blending should help teaching and performance professionals create and manage plans to make the best use of FTF and technological formats, selecting the optimum instructional or non-instructional performance solutions (Yoon \& Lim, 2007).

Despite the fact that online learning is a widely used learning practice with many strategic advantages, FTF and online learning are still side by side in the educational world. Some researchers believe that there will always be a place for instructor-led educational programs. Others believe that online learning is more successful than FTF learning, and may therefore possibly take the place of FTF learning in the future. When we look at the literature, we find many advocates of these two opinions. Researchers usually focus on students' performance, attitudes and satisfaction in their empirical studies on FTF, fully online and blended mode forms of instruction.

Russell (1999) cataloged 355 comparative studies in distance education between 1928 and 1996 and argued that no one method of delivering instruction is more effective than any other. This is known in the literature as the no significant difference phenomenon. Shen, Chung, Challis and Cheung (2007) conducted an empirical study with over 2000 students who enrolled in a master's program in the department of computing at a university in Hong Kong. The study was conducted over a four-year period, and the researchers found no significant difference in student outcomes between traditional FTF teaching and technology-delivered instruction. Hauck (2006), Liu (2007), Sweat-Guy and Wishart (2008), Finlay, Desmet and Evans (2004) and Silver and Nickel (2007) have also found the no significant difference phenomenon in their studies.

On the other hand, the empirical studies of some researchers have indicated that online education is more effective than traditional FTF education. Robertson, Grant, and Jackson (2005) examined students' perceived quality of the learning experience in online courses as compared to classroom-based learning in a graduate program. They stated that students perceived the quality of their online learning in the graduate program similar or even superior to campus courses. Guiller, Durndell, and Ross (2008) conducted a study that engaged students in a critical thinking activity using both online and FTF methods, and compared the two modes in terms of evidence for critical thinking skills. They stated that more evidence for critical thinking was found in the online condition, and more students stated that they preferred this mode of discussion.

Another emerging idea is that mixing FTF and online delivery options provides the most successful instruction. Schrum, Burbank, and Capps (2007) researched students in introductory 
teacher preparation courses and stated that the best online teacher preparation courses maybe those that blend virtual and FTF interaction, rather than those that are strictly online. According to Amrein-Beardsley, Foulger, and Toth (2007), instructors reported that the blended course model allows them to accomplish course objectives more successfully than either an online course model or a traditional course model. Most instructors noted increased interaction and contact among their students in a blended learning environment (Smith, 2005). Tang and Byrne (2007) found no significant difference in course achievement between FTF instruction and blended instruction, though they stated that students appeared to be more satisfied with the blended mode of delivery than the FTF mode of delivery.

Since blended learning is a relatively new concept in online education, relatively few studies from the literature of online instruction have looked specifically at blended courses (Delialioglu and Yildirim, 2008; Lin, 2008). This study is an empirical study that evaluates the effectiveness of the blended mode of delivery on students' achievement and attitudes towards computers in a computer literacy course.

\section{Purpose of the Study}

Purpose of this study is to compare students' course achievement and attitudes towards computers in a computer literacy course between two course delivery methods: Blended and FTF. Blended mode of instruction was selected for the experimental group, traditional FTF mode of instruction was selected for the control group. A new instructional design was utilized for the experimental and control groups based on Dick and Carey's Instructional Design Model.

To accomplish this purpose, the research questions for the study were constructed as follows: (1) Is there a significant difference between the FTF group and the blended group in terms of course achievement? and (2) Is there a significant difference between the FTF group and the blended group in terms of attitudes towards computers?

\section{Method}

\section{Design of the Study}

A pretest-posttest control group experimental design model was used in this study. The independent samples t-test was employed to determine the difference between the sample group and the control group in terms of course achievement and attitudes towards computers. The independent variable was the instructional method (FTF or blended). The dependent variables were students' course achievement and attitudes towards computers.

\section{Participants}

The participants of this study consisted of students in Uludag University's Faculty of Education. A total of 179 students were chosen for the sample. The participants consisted of 59 students from the Department of Educational Science, 34 students from the Department of Turkish Education and 86 students from the Department of Primary Education. The students were assigned to the control group and the experimental group purposefully in order to achieve 
group equivalency based on test scores examining their prior knowledge about computer literacy and attitudes towards computers. Equal representation in terms of students' prior knowledge and initial attitudes towards computers was achieved for both groups.

\section{Treatments}

In this study, a new instructional design based on Dick and Carey's Instructional Design Model was utilized for both the experimental and the control groups. Dick and Carey's Instructional Design Model was selected because it has been one of the most widely used models around the world, and it is a systematic model that defines each step in details for the instructors. Dick, Carey, and Carey (2005) state that learning is a systematic process in which every component is crucial to successful learning. Components such as instructor, learners, materials, instructional activities, delivery system and learning and performance environments interact with each other to bring about the desired student learning outcomes. A needs analysis questionnaire embedding the teaching environment, teaching methods and the content for the computer literacy course was administered to the students of both the experimental and control groups at the beginning of the experimentation. In addition to the needs analysis questionnaire, Grasha-Riechmann Learning Style Inventory was applied to both groups in order to analyze the learners' characteristics. According to the data collected from this questionnaire and the inventory, performance objectives were written, assessment instruments were developed, instructional strategies was selected, and instructional materials were developed. After these steps, the newly designed instructional course was given to the experimental and control groups.

The FTF group took the course traditionally (two hours of theoretical material in the classroom and two hours of applied material in laboratory). The theoretical part of lectures was supported by PowerPoint presentations, books, lecture notes and tutorials. Classroom discussions and question and answer techniques were used in teacher-student interactions. Teamwork, classroom discussions and projects were used in order to provide opportunities for collaborative learning. Classroom meetings for the blended group were two hours each. In addition to these classroom meetings, the blended group used a website that was developed for the course. Additional learning materials consisted of online lecture notes and multimediarich components such as screen captures, assessment simulations and online tutorials. One of the examples of screen captures and assessment simulations can be seen in Figure 1 and Figure 2. These screen captures and assessment simulations were prepared with Macromedia Captivate. There were totally fifteen flash files prepared for the course and their durations were between three and six minutes. The students in blended group were able to access these learning materials through the web site. Questions, e-mail and web announcements were used as means of student-teacher interaction. Teamwork, classroom discussions and e-mail were used in order to enhance students' collaborative learning experiences.

The website, which included the learning materials, was developed in ASP .NET 2.0 and Sql Server 2005. Macromedia Captivate was used for screen captures and assessment simulations. The website was developed like a small model of a learning management system. Students in the blended group could log in to this web site with their passwords reaching the systematically structured learning materials. 


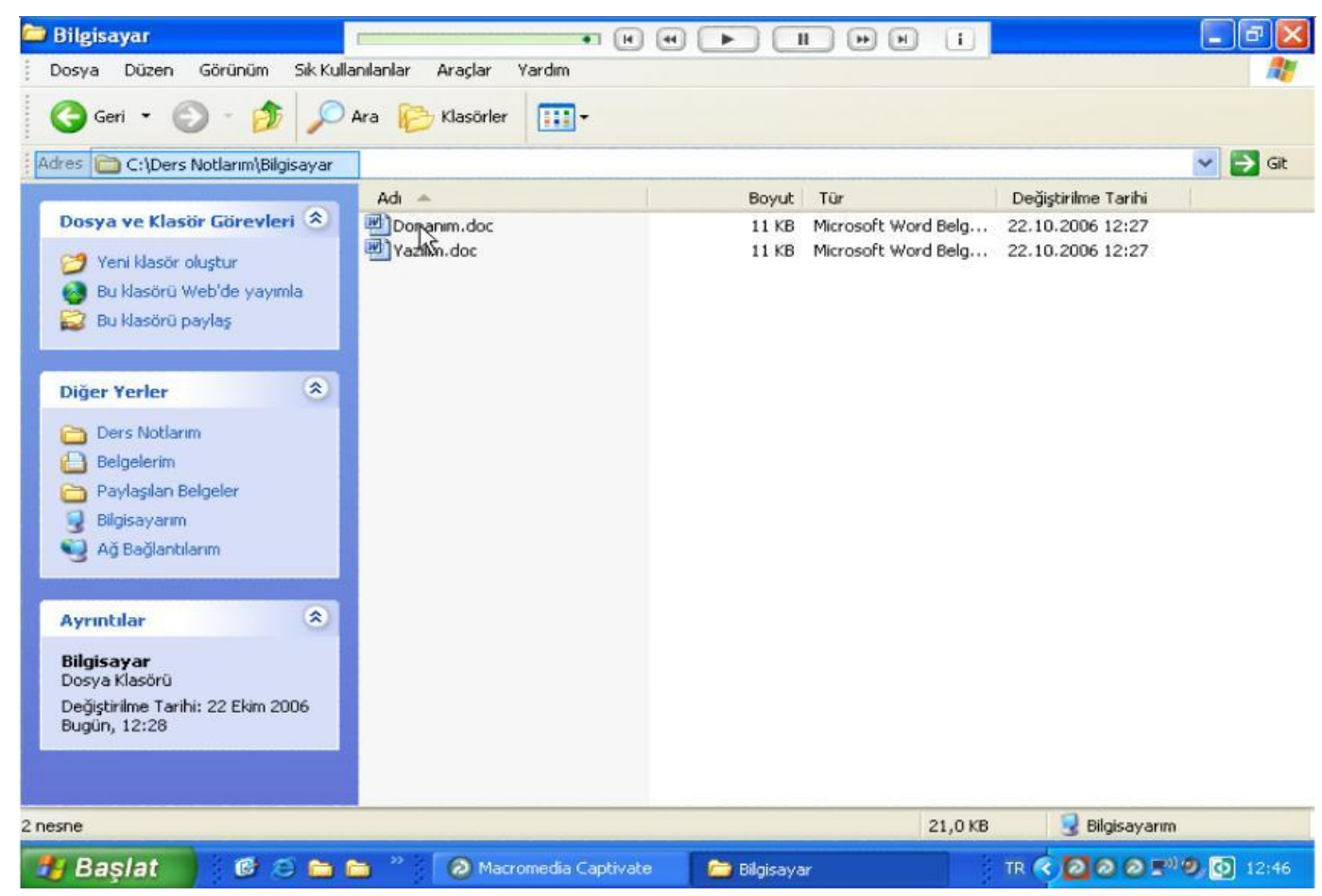

Figure 1. A screenshot of a screen capture developed in Macromedia Captivate

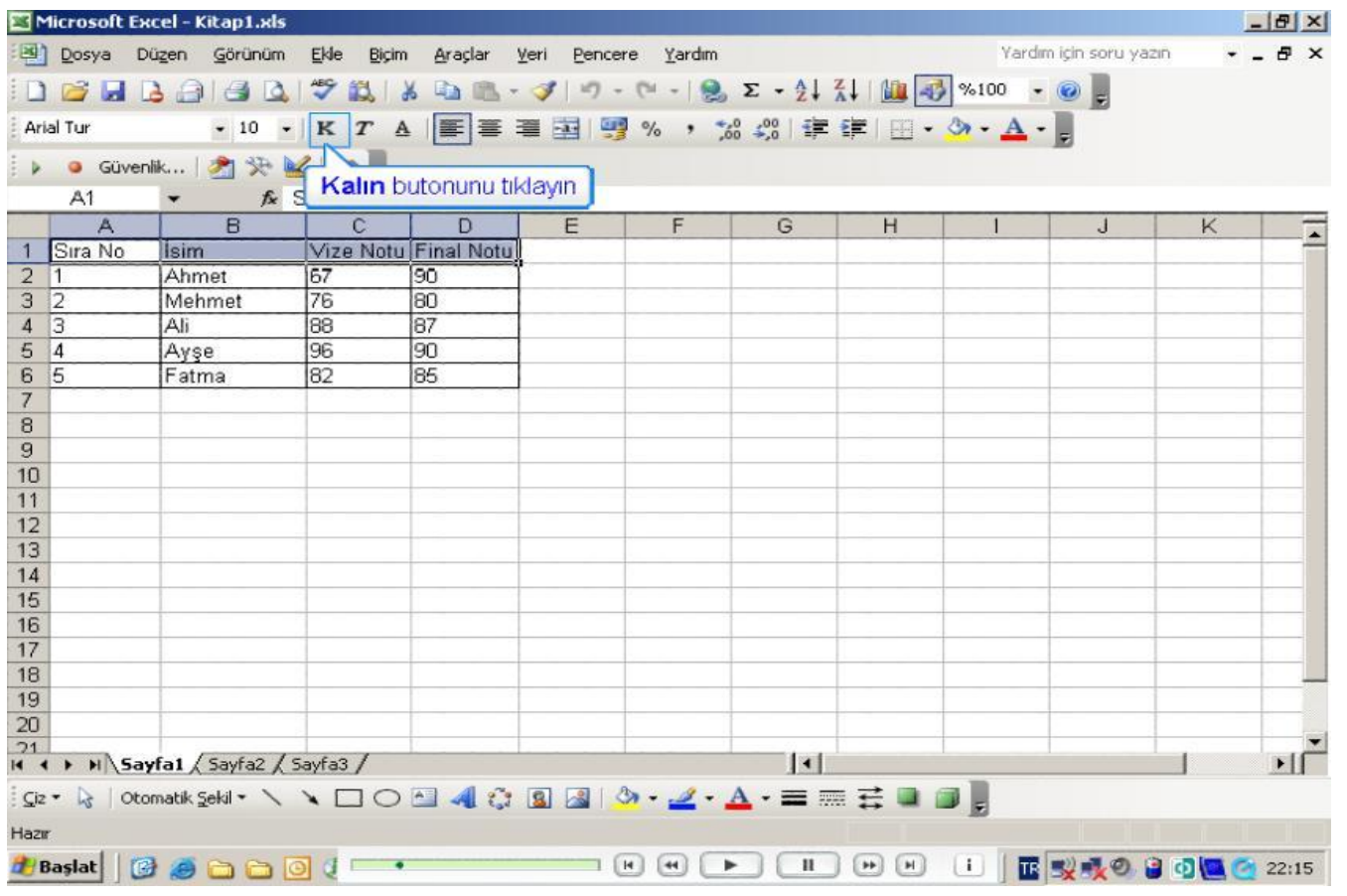

Figure 2. A screenshot of an assessment simulation developed in Macromedia Captivate 


\section{Data Collection Tools}

An achievement test and an attitude scale were used as data collection tools. The achievement test consisted of questions of final exam used in computer literacy course, and it was used to test students' prior knowledge at the beginning of the study. The same test was used at the end of the course. The test was prepared with four subject matter experts who were other instructors of the same course.

The attitude scale that was used in this study was developed by Loyd and Gressard in 1984. This scale was translated into Turkish by Berberogğlu and Çalıkoglu (1992). The scale consisted of 40 items with a four-point Likert response format; values ranged from strongly agree (4) to strongly disagree (1). The alpha reliability coefficient of the attitude scale was .90 , as shown by Berberoglu and Çalıkoglu (1992).

\section{Procedures}

A needs analysis was conducted at the beginning of the study. Performance objectives were written in light of the information gathered from the needs analysis. After that, the instructional materials were developed. At the beginning of the study, the achievement test and the attitude scale were given to the control and the experimental groups as pretests. The control group and the experimental group were then taught for 14 weeks. At the end of the course, the same test and scale were given to students as posttests. The data collected before the course and after the course were analyzed using SPSS software. An independent samples ttest was used in order to compare the groups in terms of achievement in computer literacy and attitudes towards computers.

\section{Results}

\section{Achievement}

The first research question was, "Is there a significant difference between the FTF group and the blended group in terms of course achievement?" In order to answer this question, students' prior knowledge and final achievement test results were compared. The FTF and the blended groups' pretest results (prior knowledge about computer literacy) are demonstrated in Table 1.

Table 1. Comparison of prior knowledge about computer literacy in the FTF and blended groups

\begin{tabular}{lllllll}
\hline Group & $\mathrm{N}$ & Mean & SD & $\mathrm{df}$ & $\mathrm{t}$ & $\mathrm{p}$ \\
\hline FTF & 93 & 26.173 & 13.587 & 177 & .999 & 0.319 \\
Blended & 86 & 24.071 & 14.331 & & & \\
\hline
\end{tabular}

As shown in Table 1, the independent samples t-test technique was applied to the mean pretest scores for the FTF and blended groups in order to examine the differences in prior knowledge. According to the test results, there was no significant difference in prior 
knowledge about the course between the FTF and blended groups $(p=.319)$. The FTF and blended groups' posttest results (course achievement) are shown in Table 2.

Table 2. Comparison of course achievement in the FTF and blended groups

\begin{tabular}{lllllll}
\hline Group & $\mathrm{N}$ & Mean & SD & df & $t$ & $p$ \\
\hline FTF & 93 & 51.16 & 9.97 & 177 & 6.913 & 0.000 \\
Blended & 86 & 61.49 & 10.003 & & & \\
\hline
\end{tabular}

As shown in Table 2, the independent samples t-test technique was applied to the mean posttest scores for the FTF and blended groups in order to examine the differences in course achievement. According to the test results, there was significant difference in course achievement between the FTF and blended groups $(p<.001)$. The experimental (blended) group's mean score on the achievement test was higher than the control (FTF) group's mean score.

The results indicate that the blended mode of instructional design, which was the combination of FTF and online instruction, had a positive effect on students' learning outcomes. There was no statistically significant difference in prior knowledge of computer literacy between the experimental group (blended group) and the control group (FTF group) at the beginning of the course. After 14 weeks of instruction, the experimental group received higher scores than the control group on the achievement test. The difference in the mean scores of the groups was statistically significant.

\section{Attitudes}

The second research question was, "Is there a significant difference between the FTF group and the blended group in terms of attitudes towards computers?" In order to answer this question, the Computer Attitude Scale (CAS) was applied to the FTF and blended groups at the beginning and at the end of the instructional period. The independent samples t-test technique was applied to the mean scores of both groups, and the results were compared at the significance level of .05. The comparison of the FTF and blended groups' mean CAS scores at the beginning of the instructional period are shown in Table 3.

Table 3. Comparison of the FTF and blended groups' mean CAS scores at the beginning of instruction

\begin{tabular}{lllllll}
\hline Group & $\mathrm{N}$ & Mean & SD & $\mathrm{df}$ & $\mathrm{t}$ & $\mathrm{p}$ \\
\hline FTF & 93 & 126.868 & 12.422 & 177 & .237 & .813 \\
Blended & 86 & 127.337 & 13.948 & & & \\
\hline
\end{tabular}

According to the test results shown in Table 3, there was no significant difference in attitudes towards computers between the FTF and blended groups before instruction $(p=.813)$.

The comparison of the FTF and blended groups' mean scores on the CAS at the end of instruction are shown in Table 4. 
Table 4. Comparison of the FTF and blended groups' mean CAS scores at the end of instruction

\begin{tabular}{lllllll}
\hline Group & $\mathrm{N}$ & Mean & SD & df & t & $p$ \\
\hline FTF & 93 & 124.505 & 12.180 & 177 & 3.003 & 0.003 \\
Blended & 86 & 130.535 & 14.644 & & & \\
\hline
\end{tabular}

According to the test results shown in Table 4, there was a significant difference in attitudes towards computers between the FTF and blended groups after the instruction took place $(p<.01)$.The experimental (blended) group's mean score on the CAS was higher than the control (FTF) group's mean score.

The results indicate that the blended mode of instructional design had a positive effect on students' attitudes towards computers. Before the instruction, there was no statistically significant difference in CAS mean scores between the experimental group (blended group) and the control group (FTF group). After 14 weeks of instruction, the experimental group received higher scores than the control group on the same CAS. The difference in mean scores of both groups was statistically significant.

\section{Conclusions and Implications}

This study examined the effects of blended and FTF course delivery methods on students' performance and attitudes towards computers in a computer literacy course. According to the test results, the blended mode course delivery method was more successful than the FTF course delivery method in terms of both students' course achievement and attitudes towards computers. Some possible reasons for these findings may be explained as follows.

At the beginning of the study, needs analysis and learner analysis were conducted for both groups. Performance objectives, assessment instruments, instructional strategy and instructional materials were structured based upon the needs analysis and learner analysis. Students' opinions on the contents of the course were considered. Learning activities were designed in order to achieve a learner centered environment. Teaching methods were selected by taking students' preferences, needs, and individual differences into account. The samples provided in the lessons were selected in relation to real world problems. The learner-centered approach was adopted for both groups since in a learner-centered environment students are active participants and construct their own knowledge by interacting with the information available. The only difference between the experimental (blended) and control (FTF) groups was the learning strategy, in other words, course delivery method.

The blended group used the web site containing instructional videos, screen captures, assessment simulations, reading texts, self-paced learning materials, synchronous and asynchronous communication tools and various other tools from information and communication technologies. However, the FTF group took the course with traditional learning activities such as PowerPoint presentations, books, lecture notes, tutorials, classroom discussions, and question and answer techniques.

It is believed the benefits of blended learning environment with interactive materials including instructional videos, screen captures, and assessment simulations are the most effective 
factors for success. This may be the reason why the blended group was more successful than the FTF group in both course achievement and attitudes towards computers. Literature supports that blended learning offers more successful learning environment than FTF learning. Osguthorpe and Graham (2003) stated that blended learning offers improved pedagogy, increased access to knowledge, and fostered social interaction between learners. Easy use of multiple modalities in blended learning approach provides better support for different learning styles among students (Ayala, 2009; Osguthorpe and Graham, 2003). Teachers are able to use a variety of instructional methods in blended learning environment (Vaughan, 2007) and students can control the pace of their own learning selecting the materials and managing their own times. Moreover, Garrison and Kanuka (2004) stated that "it is inevitable that campusbased higher education institutions will adopt blended leaning approaches in a significant way" (p.104). In computer literacy, there are much more skills required for practice rather than learning concepts, therefore, the students are to learn these skills by following the many guiding steps reinforcing these skills. In traditional learning environments, this is not possible for the students; however, through interactive learning materials such as screen captures and assessments simulations, it is easier for the students to watch a video and to be able to pause or rewind that video and to perform a simulation resembling the usage of a real computer in a safe environment. Of course, in FTF learning, same materials can be used in laboratory activities but in computer literacy it is not possible to make such interactions in traditional FTF learning environments as successful as in blended learning environments because in FTF learning time is limited for laboratory activities especially if the classes are crowded. In contrast in blended learning, students have flexible time to use the materials provided for them and also it is possible to better support students' individual differences and preferences. Students can be free to follow their own path in learning activities in blended learning environments.

As stated above, the findings of this study are supported by the literature: Schrum, Burbank, and Capps (2007), Amrein-Beardsley, Foulger, and Toth (2007) and Smith (2005) emphasized that the blended learning environment provides improved learning outcomes and improved student and faculty satisfaction. They also stated that faculty-student interaction and instructors' abilities to accomplish course objectives increased in the blended learning environments compared to an online or traditional course. On the other hand, researchers such as Tang and Byrne (2007) and Delialioglu and Yildirim (2008) have found no significant difference in course achievement between FTF instruction and blended instruction. Their findings of no significant difference does not conflict with the results of this research study because blended learning can be considered as successful as FTF learning according to this phenomenon. When the literature is reviewed as a whole, it can be concluded that blending online and FTF instruction, on average, produces stronger learning outcomes than FTF instruction alone (U.S. Department of Education, Office of Planning, Evaluation, and Policy Development, 2009).

Blended learning has numerous strategic advantages, such as cost effectiveness, flexibility and a reduction in students' seat time in classrooms. Although these advantages change the learning environment, the way that students learn does not change. Therefore, the theoretical framework of instruction must be considered when designing instruction; technology itself is not enough to make people learn. According to Pang (2009), technology is a tool that is strategically used in order to deliver instructional content. The focus, therefore, is on the instructional uses of technology rather than the technology itself. 
Since blended learning is a relatively new concept of online learning, there are a limited number of empirical research studies in the literature that evaluate students' learning outcomes and their attitudes. In addition, most of the research practices are from the Western world. Furthermore, these studies were conducted under different conditions and with different subjects. The present study examines an instructional practice in Turkey, comparing the effectiveness of blended and FTF learning in a computer literacy course with a sample group of pre-service teachers. It can be said that this study's originality comes from this characteristic. Of course, the study was conducted in a limited period of time (14 weeks), with a limited number of students (179 pre-service teachers) and a limited subject (a computer literacy course). Consequently, it is not possible to generalize the findings that have been obtained from the present study. Further research should be conducted on a larger group of students and with different subjects in order to achieve the best blending of online and FTF learning.

\section{Acknowledgements}

The language editing of this manuscript was done by American Journal Experts. This article is adapted from the corresponding author's doctoral dissertation. "Assisting the Computer Literacy with Web Based Instructional Design in Education Faculties" submitted to Uludag University under the supervision of Assoc. Prof. Dr. Aysan Senturk.

\section{References}

Allen, I. E., \& Seaman, J. (2004). Entering the mainstream: The quality and extent of online education in the United States, 2003 and 2004. Sloan-C.

Amrein-Beardsley, A., Foulger, T. S., \& Toth, M. (2007). Examining the development of a hybrid degree program: Using student and instructor data to inform decision-making. Journal of Research on Technology in Education, 39, 331-357.

Ayala, J. (2009). Blended learning as a new approach to social work education. Journal of Social Work Education, 45(2), 277-288. Retrieved from Academic Search Complete database.

Berberoglu, G., \& Çalıkoglu, G. (1992). Turkce bilgisayar tutum olceginin yapı geçerliliği. Egitim Bilimleri Fakultesi Dergisi , 24(2), 841-845.

Bourne, J., Harris, D., \& Mayadas, F. (2005). Online engineering education: Learning anywhere, anytime. Journal of Engineering Education, 94, 131-146.

Delialioglu, O., \& Yildirim, Z. (2008). Design and development of a technology enhanced hybrid instruction based on MOLTA model: Its effectiveness in comparison to traditional instruction. Computers and Education, 51, 474-483.

Dick, W., Carey, L., \& Carey, J. O. (2005). The systematic design of instruction. Boston: Allyn \& Bacon.

Finlay, W., Desmet, C., \& Evans, L. (2004). Is it the technology or the teacher? A comparison of online and traditional english composition classes. Journal of Educational Computing Research , 23(1), 163-180.

Garrison, D. R., \& Kanuka, H. (2004). Blended learning: Uncovering its transformative potential in higher education. Internet and Higher Education, 7, 94-105. 
Guiller, J., Durndell, A., \& Ross, A. (2008). Peer interaction and critical thinking: Face-to-face or online discussion? Learning and Instruction, 18, 187-200.

Hauck, W. E. (2006). Online versus traditional face-to-face learning in a large introductory course. Journal of Family and Consumer Sciences , 98(4), 27-29.

Lin, Q. (2008). Student satisfactions in four mixed courses in elementary teacher education program. The Internet and Higher Education, 11, 53-59.

Liu, Y. (2007). A comparative study of learning styles between online and traditional students. Journal of Educational Computing Research, 37, 41-63.

Marsh, G. E., McFadden, A. C., \& Price, B. (2003). Blended instruction: Adapting conventional instruction for large classes. Online Journal of Distance Learning Administration , 6(4).

Osguthorpe, T. R., \& Graham, R. C. (2003). Blended learning environments. Quarterly Review of Distance Education, 4(3), 227-233.

Pang, K. (2009). Instructional design strategies for effective blended learning. Journal of Interactive Instruction Development , 20(4), 3-8.

Robertson, J. S., Grant, M. M., \& Jackson, L. (2005). Is online instruction perceived as effective as campus instruction by graduate students in education? Internet and Higher Education, 8, 73-86.

Russell, T. (1999). The no significant difference phenomenon. Chapel Hill: North Carolina State University.

Schrum, L., Burbank, M. D., \& Capps, R. (2007). Preparing future teachers for diverse schools in an online learning. The Internet and Higher Education , 10(3), 204-211.

Shen, Q., Chung, J. K., Challis, D., \& Cheung, R. C. (2007). A comparative study of student performance in traditional mode and online mode of learning. Computer Applications in Engineering Education, 15(1), 30-40.

Silver, S., \& Nickel, L. (2007). Are online tutorials effective? a comparison of online and classroom library instruction methods. Research Strategies, 20, 389-396.

Smith, G. G., \& Kurthen, H. (2007). Front-stage and back-stage in hybrid e-learning face-to-face courses. International Journal on E-Learning , 6(3), 455-474.

Smith, S. (2005). The positive and challenging aspects of learning online and in traditional faceto-face classrooms: A student perspective. Journal of Special Education Technology (20), 52-59.

Sweat-Guy, R., \& Wishart, C. (2008). A longitudinal analysis of the effects of instructional strategies on student performance in traditional and e-learning formats. Issues in Informing Science and Information Technology (5), 149-163.

Tang, M., \& Byrne, R. (2007). Regular versus online versus blended: A qualitative description of the advantages of the electronic modes and a qualitative evaluation. International Journal on ELearning , 6(2), 257-266.

U.S. Department of Education, Office of Planning, Evaluation, and Policy Development. (2009). Evaluation of evidence-based practices in online learning: A meta-analysis and review of online learning studies. Washington, D.C. 
US Report on Distance Learning. (n.d.). Retrieved June 30, 2009, from http://www.checkpointelearning.com/article/5821.html

Vaughan, N. (2007). Perspectives on blended learning in higher education. International Journal on E-Learning , 6(1), 81-94.

Yoon, S.-W., \& Lim, D. H. (2007). Strategic blending: A conceptual framework to improve learning and performance. International Journal on E-Learning , 6(3), 475-489.

Correspondence: Adem Uzun, Instructor, Department of Computer Education and Instructional Technologies, Faculty of Education, Uludag University, Gorukle, Bursa, Turkey 